Valuation Studies 5(2) 2018: 83-91

Editorial Note:

\title{
Five years! Have we not had enough of valuation studies by now?
}

\author{
Liliana Doganova, Martin Giraudeau, Hans Kjellberg, Claes- \\ Fredrik Helgesson, Francis Lee, Alexandre Mallard, Andrea \\ Mennicken, Fabian Muniesa, Ebba Sjögren and Teun Zuiderent- \\ Jerak
}

\section{A Time to Celebrate, to be Concerned, and to Have Hope}

The disparate and heterogeneous body of work that falls under the rubric of "valuation studies" has really taken off in recent years. There are a number of exciting edited volumes and special issues that have been published in the past couple of years (e.g. Berthoin Antal et al. 2015; Cefai et al. 2015; Dussauge et al. 2015; Kornberger et al. 2015). This journal, recently just an idea, is now completing Volume 5 with its tenth issue. Sometimes we hear mumbled irritations about how valuation studies are about everything-and are actually everywhere. "Victory!" we could then answer in triumph, not without noticing how the valuation of valuation studies (and, indeed, of Valuation Studies) goes hand-in-hand with a sense of academic terrain, and the occupation thereof.

Celebrations might be in order. Yet, another route strikes us as more interesting and rewarding. We think that the recent advances in valuation studies requires a pause for reflection about what this movement actually entails. Such an exercise can be used to address

The Editorial Board,editors@valuationstudies.liu.se

(C) 2018 Authors

LiU Electronic Press, DOI 10.3384/VS. 2001-5992.185283

http://valuationstudies.liu.se 
several important questions: What has the study of valuation as a social practice become? Is it possible that the proliferation of studies using a "valuation studies approach" is not a sign of success, but a sign of a field becoming formulaic and repetitive instead of diverse and innovative? 1 As valuation studies has gained currency, has it lost some of its intellectual value? Should we fear devaluation of valuation as an analytic concept? What could we possibly hope for in the years to come and what are the stakes attached to the future of valuation studies?

\section{A Largely Invisible Caveat on "Value"}

This journal, Valuation Studies, did not start with an explicit manifesto, a disciplinary doctrine or an intellectual precept. Rather, a set of suggestions-sometimes warnings-were communicated in early issues in multiple forms (e.g. Kjellberg and Mallard et al. 2013; Doganova et al. 2014; Mennicken and Sjögren 2015). One question concerned the extent to which valuation studies could (or actually should) differentiate itself from the classical thread of a sociology of values. Sociology altogether, considered in particular from the vantage point of the Weberian legacy, can be thought of as a sociology of values-i.e. a study of society understood in terms of heterogeneous groups of people attempting, beyond the sheer exercise of their instrumental rationality, to realize multiple, conflicting values (sometimes more, sometimes less successfully). Fine. But is then valuation studies just another sub-branch of sociology? A similar argument could be made with sociology's twin (evil or virtuous), namely anthropology, a disciplinary field devoted to the study of value systems (again, broadly understood). Fine, too. But this is precisely why a nuance (or an attempt at a nuance) was introduced in this journal in multiple guises, here provided in another, more abrupt manner: let us drop value, please, and also values, please, please, and focus instead on valuation.

This message was certainly picked up by some, but not by manyjudging by just a look at the way in which the subject matter has been approached in the very pages of Valuation Studies over the past few years. The purpose of moving from the study of values to the study of valuation was not to impose direction, but rather to feed new conversations and debates. Why valuation? Why a turn to value as operation, as practice, as act, as translation, as process, as movement, instead of something that something or someone just has? There are multiple reasons for this move. First, it's interesting, in the sense that it requires us to challenge and move beyond pre-existing assumptions

${ }^{1}$ This piece originated out of a sense of dismay among the members of the editorial board of Valuation Studies at the idea of valuation studies being referred to as an approach or a school. 
about values as suggested by Davis in his classic article on the topic (Davis 1971).2 Second, it brings further movement as researchers are forced to engage with and work out new positions. For contributors to a journal like Science, Technology, and Human Values for example, techno-science has always been the topic; human values often the resource. Valuation helps us problematize the very notion of values and their making. It is therefore slightly frustrating to note that in many of the instances in which a valuation studies approach is invoked, this move to valuation is often lost.

\section{A Mild Disappointment with "Economy"}

Practices of valuation come in many kinds. That is why it is rewarding to examine and discuss them within a trans-disciplinary setting. Multiple attempts at sorting them out have produced many intriguing and stimulating scholarly articulations, sometimes in terms of spheres, sometimes in terms of logics, regimes, principles, or fields (you name it), sometimes just in terms of occurrences, events or happenings. Yet, this most welcome pluralism tends to decrease quite radically when it hits the hard, monolithic wall of "the market", or "the economic". Is this simply an empirical effect? Caused by the immobility of the economic touchstone? The dominant gauge? Or does it reflect a lack of mutability on behalf of otherwise quite varying viewpoints?

True, studies dealing with economic valuations abound that demonstrate, first, the variety of conflicting metrics that operate there; and second, the multiplicity of the moral and political orientations they serve or provoke. Research in the social studies of accounting and finance, for example, has provided convincing evidence of the sharp differences in criteria (certainly all economic and also moral in a particularly differentiated manner) which can be observed if one compares, say within the same investment bank, a financial analyst, a human resource manager, a compliance officer, a computer trading engineer and a lawyer (Beunza and Stark 2004; Lépinay 2011; Ortiz 2014; Godechot 2016). The same could be said of studies that examine the practices and justifications of different metrics in the (economic) appraisal of environmental impact (e.g. Fourcade 2011). Nonetheless, quite a large number of contributions which are intended to fall within the area of valuation studies seems to consider the economic as a univocal valuation principle that contrasts with everything else. Yet, in our view, one of the main purposes of valuation studies was exactly to query such concepts and compartmentalizations of the world (see also Kurunmäki, Mennicken and Miller 2016). Among other things, Valuation Studies was founded to explore new ways of questioning the

2 See Davis (1971: 327): “[...] the criterion by which an audience judges a particular proposition to be interesting is that it denies some aspect of their assumptionground." 
very make-up of the economic in economic valuation, or as Hopwood (1992) would put it, to give insight into the "shifting sphere of the economic". Perhaps the economic connotations of valuation are stickier than we had envisioned. We might also join Helmreich (2008) in asking how we could destabilize the economic or capital as "refusing to trust that exchange as such can permit the adequation of different values" (p. 475).

\section{A Blatant Lack of "Lack"}

What is absent can be as telling as what is present. Yet, bringing absences into the discussion is not without its contradictions as, at the same time, it necessarily creates new absences (see e.g. Rappert 2014). That said, there are a number of empirical domains, conceptual approaches, and modes of writing that are blatantly lacking in the pages of this journal as well as in the broader field of which it wants to be part.

Contrasts can be useful here. Contemplate for instance the extent of the attention paid to matters pertaining to research and higher education as compared to other educational settings. Our conversations, in print as well as in small talk, do recurrently touch upon the plethora of valuation practices present in academia and higher education (e.g. Pontille and Torny 2014; Espeland and Sauder 2016; Helgesson 2016; Fochler and de Rijcke 2017). Compare this with the attention paid to valuation practices in education more broadly-from the grading of schoolchildren, the possible rating of schools by the Programme for International Student Assessment (PISA) run by the Organization for Economic Co-operation and Development (OECD). We are not arguing that research on the latter does not exist. What we $d o$ argue is that research about these matters is broadly absent in the scholarly conversations that take place under the rubric of valuation studies.

We could go on to list other empirical domains that are glaringly absent in our field. We will not. Our purpose in talking about absences is not to create lists of absences. Such exercises could easily instil a sense that greater completeness could be reached if only this, that, and the other domain were more clearly folded into our conversations-a version of the etcetera problem. The many absent domains, above exemplified by (primary and secondary) education, should in our view instead be used to pose pressing questions. First, how does this myopia of ours influence the scholarly endeavours that indeed are carried out under the rubric of valuation studies? For instance, and in relation to the point above, isn't it possible that our focus on specific issues and areas makes it harder for us to deconstruct the economic; and perhaps even the focus on deconstructing the economic only serves to reify it further as the coin of exchange of different species of value? What would it mean to study valuations without economies? Second, why 
are studies of valuation practices in certain domains more easily and keenly brought into our conversations while studies of other domains remain largely elsewhere? Are some issues and domains less prone to the study of valuation practices, or are we less receptive to (and accepting of) certain forms of valuation? Would other empirical fields emerge if we would, for example, speak of qualification? Third, and following on from the two previous questions, is it that valuation studies actually have little to offer to those working on domains that are absent for us? And if so, what may be headings that are more generative for them?

Another form of absences concerns conceptual approaches. We have already noted the repeated use of the notion of the valuation studies approach. Asking authors to steer away from such singularization is arguably the most common feedback we include in editorial decision letters. The presence of the singular approach speaks of telling absences. The very notion of a singular approach does not sit comfortably with us precisely because it indicates a perceived homogeneity in how to conceptually approach the study of valuation as a social practice. It indicates the risk that the study of valuation becomes conflated with a particular approach. Yet, there are already several approaches and methodologies to the study of valuation practices and their consequences. Some examples are: the promising use of conversation analysis to examine situations of valuation (Hirschauer 2014; Wagner 2015); pragmatist approaches to valuation (Muniesa 2007, 2014; Berthoin Antal et al. 2015); or political economy studies of valuation (Lindo 2017). A partial remedy would then be to further celebrate and explore differences between these approaches. More pressing, we suspect, is the need to actively promote exploration of the possibilities offered by radically different approaches (e.g. Zuiderent-Jerak and van Egmond 2015). What would a close engagement with political theory look like? Ethics? Postcolonial studies? Feminist theories? Serious game theory? Speculative design?

Absences will always be in abundant supply. Let us just say that we would like what is absent in valuation studies to shift over time. Meanwhile, absences can be mobilized to study the performativity of the very notion of valuation.

\section{A Trans-Disciplinary Challenge?}

Our reflections on the valuation studies moment and (hopefully movement) have made us ponder the signs that the field (i.e. we) is becoming formulaic with too little interest in engaging with certain empirical domains, new approaches, etc. Is valuation studies already, like so many dominant disciplines and schools of thought, experiencing the fate where exploitation is praised at the expense of 
exploration? Another, more optimistic, way to frame matters is to appreciate that these are all challenges that come from growing and shifting multi- and trans-disciplinary conversations. In such a setting, there will always be immense struggles to juggle disparate audiencesaudiences with different definitions of concepts, with interests in different empirical settings, with different sets of references and so on. An author, when publishing here, will reach a more diverse audience with different preconceptions of valuation studies than when s/he publishes in a more disciplinary focused journal. This can create telling mismatches of framing, setting and audience. This is the case for instance when (and this is not a joke) this journal receives proposals for special issues on valuation with no further specification: the proposed issue would certainly be a compelling special issue in many journals, but here special would be a misnomer, as every issue is about valuation. Likewise, the notion of a valuation studies approach might be meaningful in another journal, but on the pages of this journal it runs the danger of conflating several approaches to the study of valuation into one and to stifle discussions about conceptual differences.

We are, five years in, immersed in an interesting challenge. The field is blooming far beyond our expectations, but that makes it increasingly hard to resist professional narrowing and to stay relevant with respect to several audiences. The appeal of having a strong homogeneous identity in certain circumstances can be to the detriment of retaining the heterogeneity that is central to making the whole endeavour valuable. How can we maintain this heterogeneity within the journal? Our board includes members with affiliations to and training in a variety of disciplines-from sociology, to accounting, to anthropology, to history, to science and technology studies-and it remains very open to-and in fact extremely interested incontributions from everyone in these disciplines, and others (e.g. literary studies). Papers and special issues proposing disciplinary approaches-including concepts, empirical settings, or methodswhich are new to the journal and to us as individuals will always be given special attention. As long as the move to valuation doesn't get lost, we haven't had anywhere close to enough of this transdisciplinary challenge!

\section{Looking Ahead}

What could we possibly hope for in the years to come? Instead of ending in either self-criticism or celebration, we would like to share two of our hopes for the years to come. Let us end this with stressing a few things we hope for.

We have not had enough exploration of the possibilities and limitations of different approaches for examining and otherwise engaging with different valuation practices. We see room for more 
experimentation as well as constructive debate about the merits of different modes of doing research. These experimentations include attempts at proposing new, specifically tailored, textual and visual formats for the exploration of valuation practices. The journal is keen on keeping an open mind regarding submission formats. The editors hope to receive pieces that take forms other than those of the standardized journal article, while remaining intellectually robust and stimulating.

Nor have we had enough of exploring the many facets of valuation practices. The unpacking of "valuation machinery" still by far dominates the field. We remain very keen to unpack such machinery in new terms or in new settings. We also hope to read more from our contributors about valuation beyond its machines, for instance, studies of the political effects of valuation.

All this entails working further on how we converse under the rubric of valuation studies, as well as bringing new scholars into these conversations. We need to continue working to stimulate meaningful conversations that are inspiring and important. No, we haven't had enough of this!

\section{References}

Berthoin Antal, Ariane, Michael Hutter, and David Stark (eds). 2015. Moments of Valuation: Exploring Sites of Dissonance. Oxford: Oxford University Press.

Beunza, Daniel, and David Stark. 2004. "Tools of the Trade: The SocioTechnology of Arbitrage in a Wall Street Trading Room.” Industrial and Corporate Change 13(2): 369-400.

Cefai, Danile, Martin Endress, Stefan Nicolae, and Bénédicte Zimmermann. 2015. "Introduction: Special Issue on Sociology of Valuation and Evaluation." Human Sciences 38(1): 1-12.

Davis, Murray S. 1971. "That's Interesting! Towards a Phenomenology of Sociology and a Sociology of Phenomenology." Philosophy of the Social Sciences 1(2): 309-344.

Doganova, Liliana, Martin Giraudeau, Claes-Fredrik Helgesson, Hans Kjellberg, Francis Lee, Alexandre Mallard, Andrea Mennicken, Fabian Muniesa, Ebba Sjögren, and Teun Zuiderent-Jerak. 2014. "Editorial note: Valuation Studies and the Critique of Valuation." Valuation Studies 2(2): 87-96.

Dussauge, Isabelle, Claes-Fredrik Helgesson, and Francis Lee (eds). 2015. Value Practices in the Life Sciences and Medicine. Oxford: Oxford University Press. 
Espeland, Wendy Nelson, and Michael Sauder. 2016. Engines of Anxiety: Academic Rankings, Reputation, and Accountability. New York: Russell Sage Foundation.

Fochler, Maximilian, and Sarah De Rijcke. 2017. "Implicated in the Indicator Game? An Experimental Debate.” Engaging Science, Technology, and Society 3: 21.

Fourcade, Marion. 2011. "Cents and Sensibility; Economic Valuation and the Nature of "Nature"." American Journal of Sociology 116 (6): 1721-1777.

Godechot, Olivier. 2016. "Back in the Bazaar: Taking Pierre Bourdieu to a Trading Room.” Journal of Cultural Economy 9(4): 410-429.

Helgesson, Claes-Fredrik. 2016. "Editorial Note: Folded Valuations?" Valuation Studies 4(2): 93-102.

Helgesson, Claes-Fredrik, Monika Krause, and Fabian Muniesa. 2017. "Editorial Note: Attempting to Bring Valuation and Politics Together the Politics of Valuation Studies at a Series of Sessions in Copenhagen." Valuation Studies 5(1): 1-6.

Helmreich, Stefan. 2008. "Species of Biocapital." Science as Culture 17(4): 463-478.

Hirschauer, Stefan. 2014. "How Editors Decide. Oral Communication in Journal Peer Review." Human Studies 38(1): 37-55.

Hopwood, Anthony G. 1992. "Accounting Calculation and the Shifting Sphere of the Economic.” European Accounting Review 1(1): 125-143.

Kjellberg, Hans, Alexandre Mallard, Diane-Laure Arjaliès, Patrik Aspers, Stefan Beljean, Alexandra Bidet, Alberto Corsin, Emmanuel Didier, Marion Fourcade, Susi Geiger, Klaus Hoeyer, Michèle Lamont, Donald MacKenzie, Bill Maurer, Jan Mouritsen, Ebba Sjögren, Kjell Tryggestad, François Vatin, and Steve Woolgar. 2013. "Valuation Studies? Our Collective Two Cents." Valuation Studies 1(1): 11-30.

Kornberger, Martin, Lise Justesen, Anders Koed Madsen, and Jan Mouritsen (eds). 2015. Making Things Valuable. Oxford: Oxford University Press.

Kurunmäki, Lisa, Mennicken, Andrea, \& Miller, Peter. 2016. "Quantifying, economising, and marketising: democratising the social sphere?" Sociologie Du Travail, 58(4), 390-402.

Lépinay, Vincent-Antonin. 2011. Codes of Finance: Engineering Derivatives in a Global Bank. Princeton, NJ: Princeton University Press.

Lindo, Duncan. 2017. "Why Derivatives Need Models: The Political Economy of Derivative Valuation Models." Cambridge Journal of Economics https://doi.org/10.1093/cje/bex055.

Mennicken, Andrea, and Ebba Sjögren. 2015. "Editorial Note: Valuation and Calculation at the Margins." Valuation Studies 3(1): 1-7.

Muniesa, Fabian. 2007. "Market Technologies and the Pragmatics of Prices." Economy and Society 36: 377-395.

- - 2014. The Provoked Economy: Economic reality and the performative turn. London: Routledge.

Ortiz, Horacio. 2014. "The Limits of Financial Imagination: Free Investors, Efficient Markets, and Crisis.” American Ethnologist 116(1): 38-50. 
Pontille, David, and Didier Torny. 2014. "From Manuscript Evaluation to Article Valuation: The Changing Technologies of Journal Peer Review." Human Studies 38(1): 57-79.

Rappert, Brian. 2014. "Present Absences: Hauntings and Whirlwinds in "Graphy"." Social Epistemology 28(1): 41-55.

Wagner, Lauren B. 2015. “"Tourist Price” and Diasporic Visitors: Negotiating the Value of Descent." Valuation Studies 3(2): 119-148.

Zuiderent-Jerak, Teun, and Stans van Egmond. 2015. "Ineffable Cultures or Material Devices: What Valuation Studies Can Learn from the Disappearance of Ensured Solidarity in a Health Care Market." Valuation Studies 3(1): 45-73.

This text has been jointly authored by the members of the editorial board of Valuation Studies: Liliana Doganova (associate professor, Centre de Sociologie de l'Innovation, Mines ParisTech, France), Martin Giraudeau (assistant professor, Department of Accounting, London School of Economics and Political Science, United Kingdom), ClaesFredrik Helgesson (professor, Department of Thematic StudiesTechnology and Social Change, Linköping University, Sweden), Hans Kjellberg (professor, Department of Marketing and Strategy, Stockholm School of Economics, Sweden), Francis Lee (researcher, Department of History of Science and Ideas, Uppsala University, Sweden), Alexandre Mallard (professor, Centre de Sociologie de l'Innovation, Mines ParisTech, France), Andrea Mennicken (associate professor, Department of Accounting, London School of Economics and Political Science, United Kingdom), Fabian Muniesa (professor, Centre de Sociologie de l'Innovation, Mines ParisTech, France), Ebba Sjögren (associate professor, Stockholm University, Sweden), and Teun Zuiderent-Jerak (associate professor, Department of Thematic Studies -Technology and Social Change, Linköping University, Sweden). 